\title{
Integration of LCA in the Planning Phases of Adaptive Buildings
}

\author{
Friederike Schlegl ${ }^{1, *}$, Clemens Honold ${ }^{2}$, Sophia Leistner ${ }^{3}$, Stefan Albrecht ${ }^{4} \oplus$, Daniel Roth ${ }^{2}$, \\ Walter Haase ${ }^{3}$, Philip Leistner ${ }^{1,4}$, Hansgeorg Binz ${ }^{2}$ and Werner Sobek ${ }^{3}$ \\ 1 Department of Life Cycle Engineering (GaBi), Institute for Acoustics and Building Physics (IABP), \\ University of Stuttgart, Wankelstraße 5, 70563 Stuttgart, Germany \\ 2 Institute for Engineering Design and Industrial Design (IKTD), University of Stuttgart, Pfaffenwaldring 9, \\ 70563 Stuttgart, Germany \\ 3 Institute for Lightweight Structures and Conceptual Design (ILEK), University of Stuttgart, \\ Pfaffenwaldring 7, 70569 Stuttgart, Germany \\ 4 Department of Life Cycle Engineering (GaBi), Fraunhofer Institute for Building Physics (IBP), \\ Nobelstraße 12, 70563 Stuttgart, Germany \\ * Correspondence: friederike.schleg1@iabp.uni-stuttgart.de; Tel.: +49-711-970-3171
}

Received: 24 June 2019; Accepted: 6 August 2019; Published: 8 August 2019

\begin{abstract}
The high consumption of resources in the building industry requires a significant reduction of material in buildings and consequently a reduction of emissions over all phases of the life cycle. This is the aim of the Collaborative Research Centre 1244 Adaptive Skins and Structures for the Built Environment of Tomorrow, funded by the German Research Foundation (DFG), which addresses research on the development and integration of adaptive systems in building structures and skins. New approaches in building planning are required for the implementation of adaptive buildings. Therefore, a multidisciplinary team from various fields such as architecture, civil and mechanical engineering, and system dynamics is necessary. The environmental impacts of the whole life cycle have to be considered for an integral planning process for adaptive buildings right from the beginning. For the integration of the Life Cycle Assessment (LCA), four temporal and content-related interfaces were identified in the planning process. Inputs and outputs of the LCA were defined for the relevant planning stages in order to enable the greatest possible benefit for the planners and to minimize the environmental impacts as far as possible. The result of the research work is a methodology that can be used in the future to reduce life cycle-related environmental impacts in the planning process of adaptive buildings (ReAdapt).
\end{abstract}

Keywords: LCA; planning process; adaptive buildings; environmental impacts

\section{Introduction}

Driven by environmental concerns, the limitation of resources, and the increase of emissions, the construction industry is currently experiencing innovative change [1]. Due to the above issues and the target of not exceeding the $1.5^{\circ} \mathrm{C}$ limit of global warming, new approaches for the buildings of tomorrow are required. The integration of adaptive elements into building structures offers the opportunity to save materials and reduce emissions. Adaptive buildings therefore represent an approach geared to significantly reduce considerable resource requirements of the building industry in all phases of the life cycle, thus reducing its environmental impact. The integration of actuators such as hydraulic cylinders into supporting structures enables them to achieve small displacements and allows for the manipulation of forces in the supporting structure to reduce maximum stresses of structural components. As a result, induced peak stresses caused by earthquakes or winds can be reduced, oscillations can 
be damped, and the dimension of structural components can be decreased by homogenizing the load transfer. By integrating actuators and sensors into façade systems, the building skin can also be transformed from a typically static system into a dynamic one, for example, by regulating air, light, and heat permeability in real-time as required. With the integration of adaptive elements into load-bearing structures and skins, the building is able to react to changes in the environment and on differing user demands [2,3].

Compared to conventional buildings, a level of complexity and increased effort are required for the planning of adaptive buildings, leading to a higher planning expenditure. Adaptive buildings require the integration of complex technologies from mechanical engineering, system technologies, and computer science. As a result, interdisciplinary or integral planning processes must be developed to deal with new challenges resulting from the interfaces of disciplines and tasks [4]. Compared to conventional buildings, adaptive buildings have even higher maintenance requirements. Buildings are planned specifically according to their use and environment, meaning each building has to be planned individually. Especially for an adaptive structure, the potential for saving resources must be determined separately. These potentials have to be compared to the explained additional effort during planning and operation.

In order to identify the location-related potential for adaptive buildings right from the beginning of the planning process, it is necessary to analyze the environmental impacts directly. A suitable instrument to analyze the environmental impact is the standardized method of the life cycle assessment (LCA) according to $[5,6]$. By applying the LCA method, it is possible to examine the environmental performance of buildings over their entire life cycle and to consider all the resources used. The LCA results are shown as environmental impacts grouped into impact categories. These results can then facilitate the identification of environmental hot-spots, as well as the comparison of construction variants.

In recent years, research and development has been carried out to significantly reduce the operational energy use of buildings and the resulting environmental impacts in the use phase. The life cycle of buildings is defined in DIN EN 15978 [7], which is split into the main phases of the product and construction phase (A1-A5), use phase (B1-B5: use, maintenance repair, replacement, refurbishment; B6-B7: operational energy and water use), end of life phase (C1-C4), and the potential benefits and loads beyond the buildings life cycle-related to reuse, recovery, and recycling (D). Figure 1 shows in the first three bars the development of life cycle-related greenhouse gas emissions from buildings realized in EnEV standard via passive house construction to plus-energy houses. The results are divided into Construction and Operation according to the German Sustainable Building Council System [8]. In Figure 1, Construction summarizes the life cycle related greenhouse gas emissions from A1-A5; $\mathrm{B} 1-\mathrm{B} 5, \mathrm{C} 1-\mathrm{C} 4$ and $\mathrm{D}$, while Operation comprises the greenhouse gas emissions from the operational energy use of heating, cooling, and ventilation.

While significant reductions were achieved in operational energy use, efforts for the Construction increased significantly. The research and development of adaptive buildings aims to significantly reduce the life cycle-related resource requirements and environmental impacts of Construction without significantly increasing the additional operation energy use of adaptive skins and structures, as the right bar of Figure 1 indicates. 


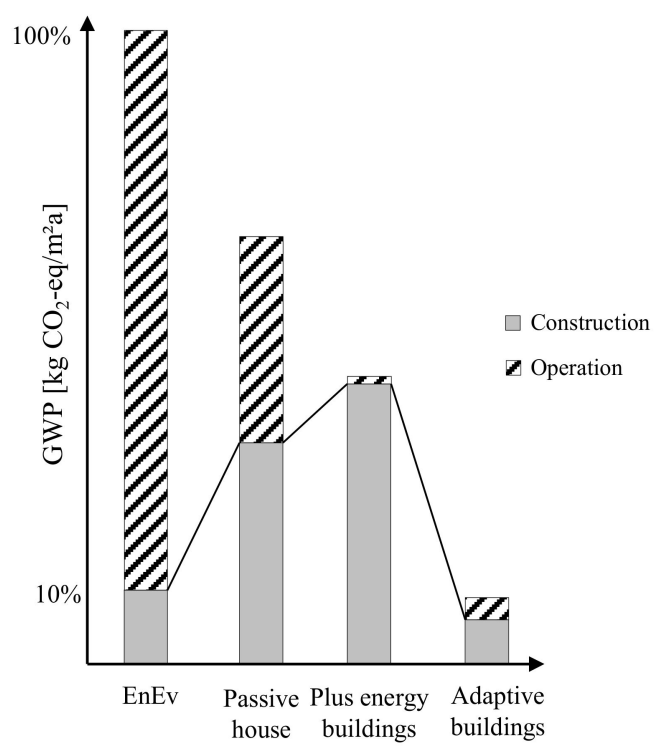

Figure 1. Comparison of adaptive buildings and energy-efficient building concepts concerning the related Global Warming Potential (GWP) for Construction and Operation [9].

In the Collaborative Research Centre (SFB) which was established at the University of Stuttgart in 2017, concepts for adaptive skins and structures with their respective potentials and challenges are investigated. An essential part of the research project is the construction and realization of a $36 \mathrm{~m}$ high experimental high-rise building, which will be located on the campus of the University of Stuttgart [10]. This building serves as demonstrator to prove the functionality of all adaptive components, the effectiveness of the concept of adaptivity, and the developed planning methodology.

\section{Problem and Goal Definition}

The anticipated resource efficiency of adaptive buildings is a decisive argument for this type of building. However, integral planning in a multidisciplinary team is a complex and demanding task. The planning of the experimental high-rise building has revealed various challenges that must also be met in future planning projects. In particular, the novelty and challenge of the evaluation of adaptive building concepts are related to a lack of knowledge about the environmental impacts so that these aspects have to be investigated systematically in the respective planning process. For the planning of adaptive buildings, the planning participants need a methodology that supports them in the systematic investigation and reduction of environmental impacts. Different methods and existing approaches need to be combined, forming a novel methodology.

The following research question is answered in the article: At which stage and at which detail level of the planning process of adaptive buildings is an assessment of life cycle-related environmental impacts possible with the respective information available? The aim of the introduced methodology is to reduce environmental impacts right from the beginning in the first planning stage of adaptive buildings. In order to answer the research question, aspects from life cycle assessment, architecture, and process development must be considered.

The main goal of this article is to introduce the developed methodology allowing an assessment of the environmental impacts at different stages within the planning process. Starting with the basic evaluation of the project in the planning phase, an assessment of the potential for resource efficiency is possible. The efficiency of the adaptive building must be evaluated repeatedly along the progressing development of the design and all planning tasks.

In the longer term, experience values for the planning of adaptive buildings will be available and collected. Therefore, the evaluation after the realization of the building based on material use and final energy demand during the operation is planned. The evaluation with the measured date 
can then serve as an actual comparison with the estimates made during the planning phases with the methodology described in this article.

\section{Research Approach and Structure of the Article}

This section presents the structure of the subsequent content of the paper and the respective research approaches. The research procedure is summarized in Figure 2. In Section 4, the essential basics are determined by a literature review and discussions with experts in the field of sustainability assessment and building planning are presented. First, the basics include a description of the typical conventional planning procedure (Section 4.1) and a summary of the existing, context-relevant methods for environmental building planning (Section 4.2). In Section 4.3, already identified deviations in building planning are presented with regard to the intended adaptivity. In this context, the findings from the planning of the experimental high-rise building, which affect the planning of adaptive buildings, are summarized. Interfaces are shown therein that serve as approaches for the integration of the evaluation of the environmental impacts. Based on this, the need for the assessment methodology is specified in Section 5 in the form of a requirements definition. These findings were largely gained during the planning of the high-rise and during the analysis, which interfaces exist between the planning, and the analysis of environmental impacts. Section 6 presents the developed methodology in detail. The main aspects, intermediate results, and interfaces to the planning phases are explained. In order to validate the results, the methodology was applied retrospectively in the planning context of the experimental high-rise building. Section 7 presents and discusses the results of this validation. The challenges identified during the validation and interpretation of the results are then explained. The article closes in Section 8 with a conclusion and an outlook with regard to subsequent research activities.

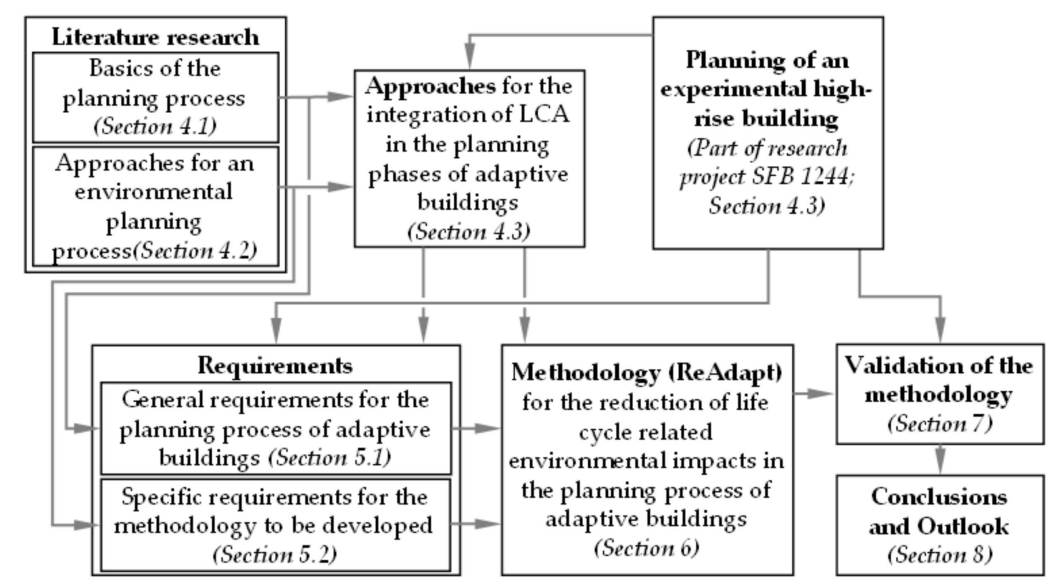

Figure 2. Content and structure of the article.

\section{Literature Research}

The subsequently described literature research was focused on the investigation of the boundary conditions in the common building planning processes in Germany and the existing approaches for integral planning procedures. Based on thereby derived findings, changes to the conventional planning processes could be identified and will be presented adjacently.

\subsection{Basics of Planning Processes and Related Service Phases of Buildings}

Planning in the construction industry can be understood as a process for solving specific problems, starting with a planning impulse through to the preparation of a plan and ending with the execution and operation of the building [11]. The planning process in Germany is generally based on the Official Scale of Fees for Services by Architects and Engineers (German abbreviation HOAI), which is mandatory for public building projects [12]. The HOAI determines the remuneration based on performance profiles 
and is divided into nine service phases, which are represented as being processed sequentially. Table 1 lists the service phases in the first column, as well as their proportion of the overall performance of the architect, which in total corresponds to $100 \%$ overall nine phases. In the second column, the performance profiles, and responsibilities for each service phase are briefly summarized and therefore provide a rough insight into the conventional building planning procedure.

Table 1. Service phases of the fee structure with the corresponding fee portion and relevant task specification of the architect [13-15].

\begin{tabular}{|c|c|}
\hline $\begin{array}{l}\text { Service Phases According to HOAI (2013) } \\
\text { with Each Percentages Out of Total Services }\end{array}$ & Performance Profiles and Responsibilities \\
\hline $\begin{array}{c}\text { 1. Basic Evaluation } \\
3 \%\end{array}$ & $\begin{array}{l}\text { Clarification and familiarization with the planning task, definition of } \\
\text { the framework conditions of the project and inquiry for specialist } \\
\text { engineers to be integrated [13]. }\end{array}$ \\
\hline $\begin{array}{l}\text { 2. Preliminary Design } \\
7 \%\end{array}$ & $\begin{array}{l}\text { Creative brainstorming, creation of design variants, incorporation } \\
\text { into the planning procedure, creation of preliminary design in the } \\
\text { form of drawings, integration of consulting services by specialist } \\
\text { engineers [13]. }\end{array}$ \\
\hline $\begin{array}{l}\text { 3. Detail and Final Design } \\
\qquad 11 \%\end{array}$ & $\begin{array}{c}\text { Concept selection and detailing of the preliminary design involving } \\
\text { all specialist engineers; the result is a planning concept including } \\
\text { every defined component as a basis for the building permission } \\
\text { application [13]. }\end{array}$ \\
\hline $\begin{array}{l}\text { 4. Building Permission Application } \\
6 \%\end{array}$ & $\begin{array}{l}\text { Completion of approvable plans in cooperation by necessary } \\
\text { planning participants and presentation of the design for the } \\
\text { submission to the law authorities with the aim to obtaining } \\
\text { preliminary construction permission [13]. }\end{array}$ \\
\hline $\begin{array}{l}\text { 5. Execution Planning } \\
25 \%\end{array}$ & $\begin{array}{l}\text { Creation of execution plans based on detail and final design as } \\
\text { preparation for the realization of the building e.g., floor plans and } \\
\text { sections in a scale form of 1:50 up to 1:1 for the details [13]. }\end{array}$ \\
\hline $\begin{array}{c}\text { 6. Preparation of Contract Award } \\
10 \%\end{array}$ & $\begin{array}{c}\text { Preparation of performance specifications and lists based on } \\
\text { quantity determinations with the aim of identifying all quantities of } \\
\text { components; materials and elements for the summarizing in } \\
\text { a register [14]. }\end{array}$ \\
\hline $\begin{array}{l}\text { 7. Assisting with the Awarding Process } \\
4 \%\end{array}$ & $\begin{array}{l}\text { Requesting and reviewing tenders for bidders in negotiations with } \\
\text { construction firms on the basis of performance specifications. } \\
\text { Subsequent tendering of all necessary materials and awarding of } \\
\text { contracts to the construction firms [14]. }\end{array}$ \\
\hline $\begin{array}{l}\text { 8. Project Supervision } \\
31 \%\end{array}$ & $\begin{array}{l}\text { Start of the realization process and the control of it, in the form of } \\
\text { site supervision. Examination of construction defects, control of } \\
\text { costs and time schedule during the construction phase. The aim is } \\
\text { the completion and the delivery of the building to the client [14]. }\end{array}$ \\
\hline $\begin{array}{l}\text { 9. Project Control and Documentation } \\
\qquad 3 \%\end{array}$ & $\begin{array}{l}\text { In this phase, the building is supervised and defects are remediated } \\
\text { based on a legal guarantee over a limitation period of } 5 \text { years [15]. }\end{array}$ \\
\hline
\end{tabular}

In the practice of the construction industry, however, the planning procedure shows differences to the described approach in the HOAI. The actual procedure does not represent a linear sequence of decisions, but rather a structure of networked, iterative processes. The content of the fee structure is also performance-related and not occupation-related, whereby the relevant interfaces are undefined [16]. In addition, public procurement law provides the segregation of activities between design and execution. Both aspects result in a reduced exchange of information among the planning participants. With regard to the new integration of further disciplines and environmental impacts, right from the beginning, this procedure must be adjusted for a novel planning process of adaptive buildings. In addition to conventional processes, there are already approaches for integrating environmental aspects into building planning, which will be explained in more detail in the following section. 


\subsection{Existing Approaches for the Integration of LCA in the Planning Process of Conventional Buildings}

There are various approaches, which generally address environmental impacts in the design process of products. Approaches that are based on the LCA include the Materials, Energy, and Toxicity (MET) matrix, and the material input per unit of service (MIPS) concept. The MET-Matrix is intended to investigate material flows, energy consumption, and toxic emissions in the early planning process over the life cycle [17]. The MIPS concept analyzes all material input streams of a product [18].

Cabeza et al. and Hens $[19,20]$ described various challenges involved in integrating LCA into the planning process of buildings. First, the long lifetime of buildings involves a high degree of uncertainty, especially with regard to the use phase and the end of life. In addition, a building is designed individually according to its use and environmental influences so that the LCA cannot be applied in a standardized way and must be calculated individually for each building.

Finally, the usage of LCA by non-LCA experts presents challenges. These include, for example, the complexity of knowledge required to conduct an LCA, the amount of information required to analyze the whole building and detailed components, and the time required to the process [21,22].

For this reason, it is important to set, record, and observe requirements for the application of LCA in the planning process [23]. For the environmental planning of conventional buildings, Fioravanti et al. [24] formulated requirements for an architect-friendly application. These included 43 criteria, which could be divided into five subject areas: data input, output, usability in the design process, software interface, and general tool characteristics. In this way, the architect succeeds not only in minimizing the environmental impact on the basis of his experience, but also with the help of the 43 criteria.

Currently, the sustainability certification systems for buildings such as the Sustainable Building Assessment System (German abbreviation BNB) [25], the German Sustainable Building Council (German abbreviation DGNB) [8,25], the Guidance Document for energy-efficient buildings (EeB-Guide) [26], and research projects such as Integral Planning (BIM2LCA4IP) [27] based on the planning method Building Information Modeling (BIM) address different interfaces for the consideration of environmental impacts in the planning process. The BNB considers two planning phases with a simplified and complete life cycle assessment [25]. The EeB Guide, however, suggests supporting three planning phases for the integration of life cycle assessments in planning processes. The three planning phases represent a screening procedure, a simplified calculation, and a complete LCA [26]. Furthermore, the research project BIM2LCA4IP is currently investigating a direct coupling with BIM and life cycle assessments. Four planning stages have been defined where the BIM planning process is to be backed up with life cycle assessment data [27].

The aforementioned approaches show relevance of the topic to develop a planning process for more environmentally friendly buildings. In practice, complete life cycle assessments have so far rarely been carried out during the planning process. Generally, LCA is conducted after the realization of a building, i.e., at a stage when significant changes cannot be implemented anymore. However, the final energy demand in the operation is often taken into account in the design process, but if this alone is considered, the result is incomplete and one-sided [28].

\subsection{Particular Aspects for the Planning of Adaptive Buildings and Approaches for the Integration of LCA in Their Planning Phases}

Compared to conventional buildings, adaptive buildings represent a complex technical system that requires additional expertise and task areas in the planning and operation of the building [4]. These differences to conventional buildings were also confirmed during the planning and design process of the experimental high-rise building as a research assignment of the research project SFB 1244 . This building represents the world's first high-rise building with adaptive elements in its supporting structure and skin. Since autumn 2017, the University of Stuttgart has planned the realization of the building on the campus for experimental purposes. With the dimensions of the footprint at $5.2 \mathrm{~m}$ by $5.2 \mathrm{~m}$ and a height of $36 \mathrm{~m}$, the twelve-story high building has the slenderness of a skyscraper. 
Section 7 describes the experimental high-rise building in more detail. During the planning of the building, the technical feasibility was in the focus and the environmental impacts have not yet been systematically investigated.

The higher planning and operating effort for an adaptive building have to be compared to the reduction of environmental impacts for the erection of the building in a further step. The latter must be determined by LCA experts within the individual planning with regard to site-orientated framework conditions and further requirements from the use of the building. Thus, the analysis of environmental impacts and the fulfillment of requirements becomes a central task during the design and planning of adaptive buildings.

In principle, the LCA can be applied with different system boundaries within the building planning but should include the entire life cycle. The comparability of adaptive structural concepts with conventional variants generally requires a consideration of the entire structural system and the facade. This includes, on the one hand, the masses of the structural components, which together represent the only size to be considered in conventional structural systems, and which should be higher in amount for a conventional non adaptive building. On the other hand, the focus is also on the mechanical components required by the actuation concept and the resulting final energy demand. In association with the developed methodology, adaptive building skins can be considered separately as the aim is to significantly improve the physical properties of the building. The activation of the skin provides the additional option of the adaptation in terms of external environmental influences such as high and low temperatures, light, radiation, and humidity, with the aim of saving environmental impacts during the operation of the building.

Honold et al. [29] analyzed the design procedure of the experimental high-rise building. Based on acquired experience, the paper showed that a concept stage is required to jointly develop the preliminary design and the structural design, including the actuation principles and constructive actuator integration. The result of the paper was an integral design approach in the form of a procedure model with a focus on Service Phases 1-3 (Basic Evaluation, Preliminary Design, Detail, and Final Design), as shown in Figure 3. In addition to the original content, the figure illustrates the first considerations on the integration of the LCA explained below. In the procedure model, the participants of the interdisciplinary team design and develop a structural concept in direct consideration of adaptive functionalities, and the associated integration of adaptive elements. This cooperation results in structural concepts that include adaptive functionalities, user compatibility, and ensures technical feasibility. The design of the adaptive system requires an iterative approach in order to optimally consider versatile aspects of different disciplines. As an intermediate result, initial mass estimations, as well as knowledge from simulations of the actuation, are available, from which the energy demand for operating scenarios can be derived. On the basis of this data, various structural concepts should be compared with regard to their environmental impacts to enable subsequent selection (compare with the second yellow mark in Figure 3). In the following steps, at least one selected structural concept is further elaborated. The result of the iterative concept stage thus represents an interdisciplinary intermediate approach in the planning of adaptive buildings. The selected design concept has to be examined with regard to the fulfillment of environmental requirements. If the goals have not been achieved, the detailing of the design concept has to be revised to avoid increased change effort in later planning phases.

For this stage of the design process, the question must be answered as to whether the adaptive building concept or subordinate variants demonstrate the desired advantages in terms of resource efficiency. In combination with the development of a safety concept, a decision will then be made for the further realization of the adaptive building.

Since there are still many uncertainties at the concept stage and the valuation is based on preliminary estimates and forecasts, this valuation step is to be regarded as the initial target review. Evaluations in future planning steps with fewer assumptions and more precise statements are suitable for gradually concretizing and validating this initial tendency (compare with the second marking 
in Figure 3). At the latest, when the Execution Planning (Service Phase 5) has been completed, the performance specifications will be derived in Service Phase 6 (Preparation of Contract Award) and provide information on the exact mass determinations.

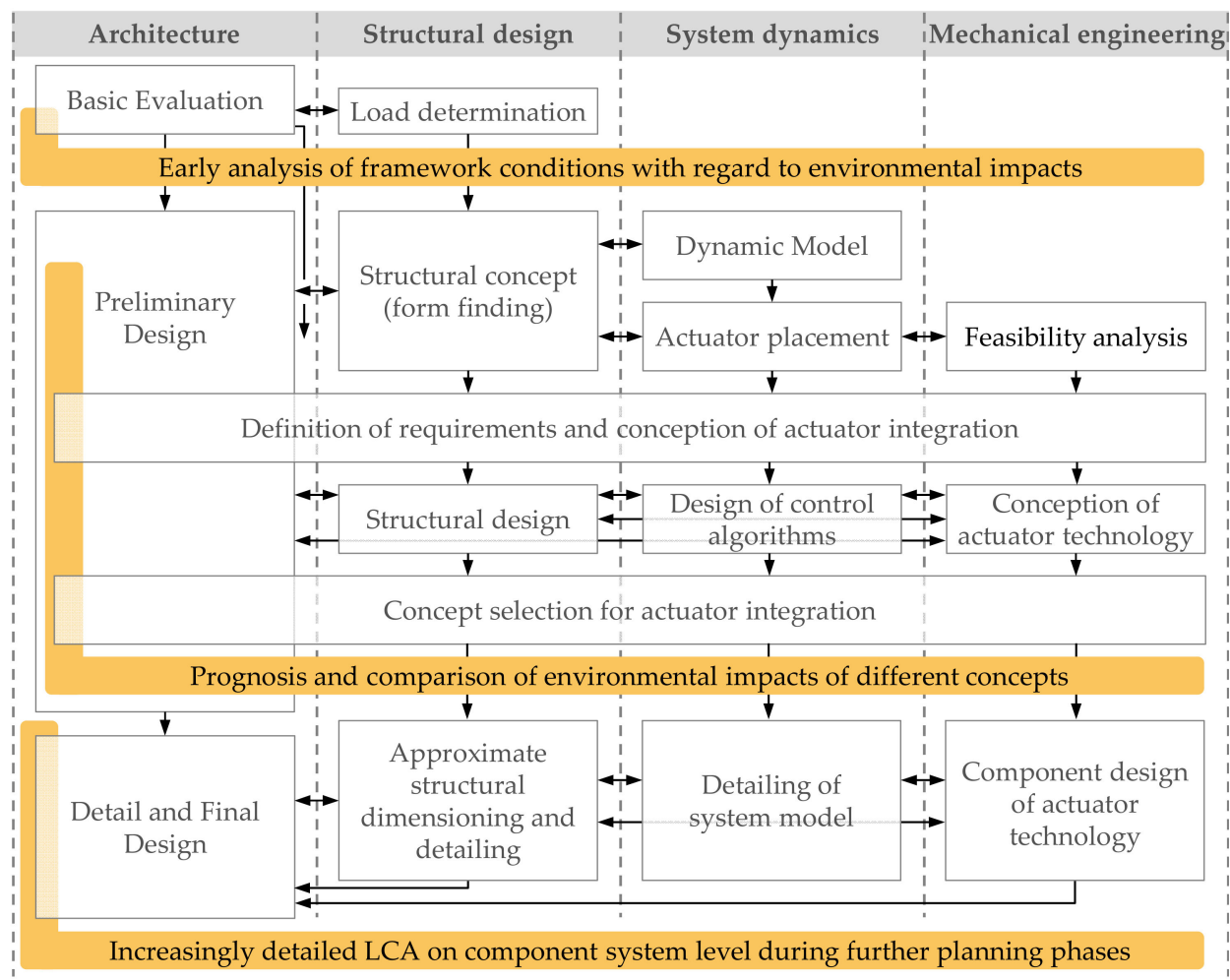

Figure 3. Procedure model of the integral design approach for adaptive structures based on [29] complemented by interfaces to integrate the Life Cycle Assessment (LCA) (yellow highlighted).

In addition to the integration of the LCA in the design phase, however, the question arises as to whether and how the LCA can be implemented directly from the beginning of the planning (compare with the first marking in Figure 3). Framework conditions such as the expected number of actuation cases are already important aspects during the design of the structure. Therefore, right at the beginning of the planning, it is necessary to examine which information is available at the corresponding stage and which information can be used in the design of the adaptive structure in the context of sustainability.

The framework conditions for the evaluation result in a procedure that delivers more accurate evaluation results with greater significance and certainty as to the detail of the planning increases. In the following sections, a model will be elaborated based on the findings of this subsection.

\section{Requirements for the Integration of LCA in the Planning Process of Adaptive Buildings}

This section summarizes the requirements that have to be fulfilled by the methodology to integrate the LCA into the planning process of adaptive buildings. The section differentiates the requirements into two subsections. The first subsection deals with already identified general requirements for the planning process of adaptive buildings. Based on this, the second subsection presents the requirements to be achieved by the methodology, which is to be developed for integration into the planning process.

\subsection{General Requirements for the Planning Process of Adaptive Buildings}

General requirements for the planning process of adaptive buildings with a focus on the early phases were identified by Honold et al. [29] based on the experience gained during the planning of the experimental high-rise building. The fulfillment of the general requirements aims for a structured 
approach and purposefully integrates necessary disciplines in the planning process. With regard to this, the context-relevant requirements are briefly presented as an overarching framework:

1. The interdisciplinary cooperation has to start with the environmental analysis of the basic evaluation directly at the beginning of the integral design process.

2. The derivation of requirements has to be performed based on the identified specifications in an interdisciplinary configuration of planning participants. If requirements have to be adjusted during the further planning process, the effects on all planning participants must be questioned, and consistent requirements management must be carried out [4].

3. The exchange of information and data between the multidisciplinary participants involved in the planning process must be ensured at specified intervals or at specified stages in the form of milestones.

4. The methodology has to be integrated into a developed method toolbox for the planning process of adaptive buildings, in which suitable application points and potentials of the methods are illustrated [30].

5. For the consideration of creative phases and iterative procedures, appropriate time periods have to be provided during the design process. The results are merged by a subsequent synthesis. In addition to the analysis of sustainability, part of the synthesis is the evaluation of safety.

The listed requirements represent a selection and are explained in detail in the publication [29].

\subsection{Specific Requirements for the Methodology for Environmental Impacts of Adaptive Buildings and Its} Integration into the Planning Process

In addition to the general aspects from the first subsection, further specific requirements are addressed to the methodology. These are intended to support the targeted development and subsequent checking of the methodology. For the identification, a workshop was conducted within the group of authors to answer the question "Which requirements for the methodology to be developed have to be fulfilled for the analysis of environmental aspects in the planning of adaptive buildings?" Subsequently, the ascertained requirements were presented, discussed, and further developed by the research team of the SFB 1244. The following list summarizes the results:

1. The methodology should systematically support the design and planning of adaptive buildings and underlying concepts with the aim of reducing life cycle-related environmental impacts.

2. Despite the different detail levels of the planning stages and the consequently various (limited) data and information basis, the methodology is intended to provide an assessment of the environmental impacts that ensures a sufficient foundation for decision-making.

3. The methodology should ensure a concretization of the evaluation results with the increasing detail level of the planning process and thus represents a compromise between a preliminary inaccurate calculation and a detailed data-based evaluation.

4. Structural concept variants, developed during the preliminary design, are supposed to be evaluated for an eventual actuation of the system. The methodology should enable a comparison of adaptation levels, which represent variants with a higher or lower number of adaptive (sub)systems.

5. The generation of a site-dependent (e.g., considering typical wind loads) and use-dependent design of a building (e.g., use as an office building) requires the individual determination of the potential for resource efficiency and, in particular, emissions savings during the methodology.

6. In principle, the methodology should include the material and energy requirements with a focus on the resulting emissions of the complete life cycle.

7. The methodology should be based on internationally recognized approaches such as LCA [5,6] to ensure the comparability with any other product system. Due to the required experience, the implementation should be carried out by specialists with expert knowledge in the field of LCA. 
8. To validate the methodology, it is necessary to assess the buildings during the operation, especially with a focus on considering the actually required, measured final energy demand. The determination enables a comparison with the forecasts made during planning and leads to a gain in experience to benefit future assessments when applying this methodology.

The requirements listed serve as the basis for the development of the methodology, which is presented step by step in the following section.

\section{Methodology for the Reduction of Life Cycle-Related Environmental Impacts in the Planning Process of Adaptive Buildings (ReAdapt)}

This section presents the methodology ReAdapt developed on the basis of the requirements described in Section 5. In addition, the procedure is based on the standardized methodology of LCA. The question to be answered is at which stage and at what level of detail an assessment of environmental impacts is possible based on the available planning information. To answer this question, the planning and design phases were first examined on the basis of the service phases according to HOAI, as explained in Section 4.1 and on the particular aspects of the planning of adaptive buildings, as explained in Section 4.3. With regard to the information available at different stages in each case, it was discussed as to which information could be used in what way from an LCA perspective. Therefore, the information was analyzed during the procedure of the typical planning process with respect to common planning tasks and their outputs. In addition, investigations were conducted as to whether planning tasks are to be brought forward or extended for their evaluability in the particular phases. Based on the results, it was analyzed as to which results of different planning stages could be assessed according to environmental impacts, which methodology has to be developed, and therefore how evaluation steps could be integrated into the planning and design process.

Figure 4 summarizes the results of the investigation, which are presented step-by-step hereafter. Section 7 describes the exemplary application of the methodology in the context of a first validation. This application was realized based on the planning information of the experimental high-rise building, which was available at the respective valuation dates.

The tabular visualization of the methodology was divided into four rows and five columns. The rows summarize six different stages of the life cycle of adaptive buildings and were derived from Section 4. The four methodology phases of ReAdapt in which the LCA is to be integrated are highlighted. The period of the methodology phases starts with the Basic Evaluation (Service Phase 1) and ends with an evaluation after the realization and operation of the building (Service Phase 9 or subsequent). The columns describe the exchange of information between the planning team and LCA-experts for each row and the generated application of it; the information included in the second column is typically available at the corresponding planning stage in column one and is used by the LCA expert as input for the evaluation. The middle column describes the implementation of the LCA with a short explanation of the abstraction degree and which product systems are examined. The outcome of the middle column represents a corresponding output with LCA results (fourth column), which should serve as an informational basis for the further planning of adaptive buildings. The fifth column describes the benefits resulting from the evaluation in the current planning phase.

In the following subsections, the individual phases of the methodology according to Figure 4 are presented in more detail, and the information typically available in the relevant planning stages and included in the evaluation is explained. 


\begin{tabular}{|c|c|c|c|c|}
\hline $\begin{array}{l}\text { Planning and } \\
\text { design stages }\end{array}$ & $\begin{array}{l}\text { Input for LCA } \\
\text { from planning }\end{array}$ & LCA implementation & $\begin{array}{l}\text { Output of LCA } \\
\text { for planning }\end{array}$ & $\begin{array}{l}\text { Benefit for design } \\
\text { and planning }\end{array}$ \\
\hline $\begin{array}{c}\text { Basic evaluation } \\
\text { and requirements } \\
\text { definition }\end{array}$ & $\begin{array}{l}\text { Framework conditions: } \\
\text { Site, usage type, gross floor } \\
\text { area, environmental influences } \\
\text { and potential adaption } \\
\text { principals }\end{array}$ & $\begin{array}{l}\text { 1) BENCHMARK LCA ON } \\
\text { BUILDING SYSTEM LEVEL: } \\
\text { Analyses of environmental } \\
\text { influences and comparison } \\
\text { with LCA-Benchmarks }\end{array}$ & $\begin{array}{l}\text { First estimation of the } \\
\text { potential of adaptive } \\
\text { systems, target definition, } \\
\text { classification with } \\
\text { benchmarks }\end{array}$ & $\begin{array}{l}\text { Estimation, whether (at least) } \\
\text { building concept is designed } \\
\text { with adaptive systems }\end{array}$ \\
\hline $\begin{array}{l}\text { Preliminary and } \\
\text { detail design }\end{array}$ & $\begin{array}{l}\text { Iterative stage with various } \\
\text { levels of detail: } \\
\text { Design concepts with floor } \\
\text { plans, sections and views, } \\
\text { structural design, rough } \\
\text { estimation of the mass } \\
\text { demand, adaption principals, } \\
\text { actuation concepts, prognosis } \\
\text { of final energy demand }\end{array}$ & $\begin{array}{l}\text { 2) PROGNOSIS LCA ON } \\
\text { FUNCTIONAL SYSTEM } \\
\text { LEVEL: } \\
\text { Determination of the expected } \\
\text { environmental impacts based on } \\
\text { the current level of detail and } \\
\text { the forecast final energy demand } \\
\text { of adaptive components by } \\
\text { external effects such as wind }\end{array}$ & $\begin{array}{l}\text { Evaluation of design } \\
\text { variants, adaption } \\
\text { principals, actuation } \\
\text { concepts and comparison of } \\
\text { variants if applicable }\end{array}$ & $\begin{array}{l}\text { Comparison of design } \\
\text { variations concerning materials, } \\
\text { adaption principle and } \\
\text { actuation concepts, final energy } \\
\text { usage or connection techniques } \\
\text { as a basis for a concept } \\
\text { selection }\end{array}$ \\
\hline Building application & $\begin{array}{l}\text { Submission of documents } \\
\rightarrow \text { no further elaboration }\end{array}$ & & & \\
\hline $\begin{array}{l}\text { Execution planning } \\
\text { and awarding } \\
\text { process }\end{array}$ & $\begin{array}{l}\text { Final design: } \\
\text { Detailed drawings of } \\
\text { materials, mass demand and } \\
\text { expected final energy demand } \\
\text { based on performance } \\
\text { specifications }\end{array}$ & $\begin{array}{l}\text { 3) DETAILED LCA ON } \\
\text { COMPONENT SYSTEM } \\
\text { LEVEL: } \\
\text { Determination of the expected } \\
\text { environmental impacts based } \\
\text { on the final design by external } \\
\text { effects such as wind }\end{array}$ & $\begin{array}{l}\text { Evaluation of the final } \\
\text { design including adaptive } \\
\text { systems; calculation based } \\
\text { on material and mass } \\
\text { description and on prognosis } \\
\text { of final energy demand } \\
\text { during operation }\end{array}$ & $\begin{array}{l}\text { Review of the adaptive system } \\
\text { with regard to material and } \\
\text { emission savings, comparison } \\
\text { with target definition }\end{array}$ \\
\hline $\begin{array}{l}\text { Construction and } \\
\text { project monitoring }\end{array}$ & $\begin{array}{l}\text { Construction process } \\
\rightarrow \text { no further elaboration }\end{array}$ & & $\begin{array}{l}\text { Subsequent adaptations usually } \\
\text { lead to high modification costs }\end{array}$ & \\
\hline $\begin{array}{l}\text { Project supervision } \\
\text { and building } \\
\text { operation }\end{array}$ & $\begin{array}{l}\text { Completed construction: } \\
\text { Measurement results of the } \\
\text { actual final energy demand in } \\
\text { the operating phase, actual } \\
\text { material quantities needed, } \\
\text { insights from building } \\
\text { monitoring }\end{array}$ & $\begin{array}{l}\text { 4) COMPLETE LCA ON } \\
\text { OVERALL SYSTEM LEVEL: } \\
\text { Determination of the actual } \\
\text { environmental impacts based } \\
\text { on the completed construction } \\
\text { and building in operation }\end{array}$ & $\begin{array}{l}\text { Evaluation of the building } \\
\text { on the basis of objective } \\
\text { measurement results of } \\
\text { environmental impacts }\end{array}$ & $\begin{array}{l}\text { Comparison of prognosis and } \\
\text { actual situation: } \\
\text { Validation of the evaluation } \\
\text { procedure; basis for a } \\
\text { certification and feedback of the } \\
\text { results in the form of a reference } \\
\text { example (for the database) }\end{array}$ \\
\hline
\end{tabular}

Figure 4. Overview of the methodology phases for the resource-efficient evaluation of adaptive buildings. 


\subsection{Phase 1: Screening LCA on Building System Level}

The first assessment phase of the methodology is carried out within the Basic Evaluation (Service Phase 1). This phase includes the definition of framework conditions, where object-oriented examination by the LCA is not possible. During the Basic Evaluation, as general information, only the framework conditions of the urban environment and building specific outline requirements are recognized such as the location or site of the building, the required floor space, and the type of use. Based on this, further information can be identified such as site-specific external loads, e.g., resulting from wind or earthquakes. The weather data (e.g., the strength of winds and their frequencies of occurrence plotted by the German Weather Service) or wind map terrain categories of the Eurocode [31], as well as the seismic zonation of the Eurocode [32], serve as a support. The latter two serve as a basis for the calculation of a structural design concept and are therefore available as information for an initial evaluation. The non-permanent loads ensuing from wind or earthquakes, determined by the environmental and urban analysis, provide a decision basis for a possible actuation of the supporting structure because the adaptation of a supporting structure can be neglected if external loads are insignificant. In addition, the building typology provides information on a possible adaptation of the supporting structure, since as a result of a too-small building volume or typology (e.g., of a single-family house), the expenditure for the integration of the adaptive elements is not related to the reduction of environmental impacts.

A further approach to analyze or demonstrate the potentials of an adaptive structure is to compare the available information with LCA benchmarks of existing buildings as well as with a checklist. The checklist contains fixed criteria such as environmental influences, which are defined by the data input of this phase. The application of the checklist allows for an estimation of the potential for the integration of adaptivity and the analysis of the need for an adaptation. Benchmarks in this context represent already determined average results of LCA analysis of conventional buildings and will also include adaptive buildings. This means, for example, that in the case of buildings of similar size, typology, and external environmental influences, the load assumptions and thus the final energy demand should be comparable and predictable. In order to generate benchmarks, a statistical database with already calculated adaptive buildings has to be developed in the next step. Such databases are currently under development for conventionally certified buildings $[9,27]$ with adaptive components. The progressive planning and realization of further adaptive buildings will expand this database and increase the potential for evaluation in the Basic Evaluation (Service Phase 1).

The results of early investigation support the involved planning participants by pointing out the determined potential of an adaptive building with regard to a reduction in environmental impacts and offer decision-making assistance for the possible actuation of the supporting structure. In addition, the results can be applied to define goals and requirements for the further development of the design. These could be defined on the basis of benchmarks for a comparison criterion with other buildings.

\subsection{Phase 2: LCA on Functional System Level}

Based on the previously identified framework conditions, design variations of the building are created. This process is characterized by a highly iterative procedure and frequent changes to the building design. After the determination on a final design variant, this is elaborated and detailed in the further design process.

With regard to the requirements identified in Section 5.2, the strongly iterative procedure and the various or limited data and information basis must be considered in this phase of the methodology. Structural design variations, developed during the Preliminary Design, can be evaluated on the basis of provisional prognoses for the mass demand or on a preliminary floor plan. In addition, on the basis of this data-input, a possible actuation concept and adaption principle of the supporting structure and its resource efficiency can be verified. After the identification of potential adaptation principles and actuation concepts, the expected wind and earthquake conditions during the life cycle can be determined and the final energy demand for operation can be roughly estimated in addition to the 
material requirements. In consideration of the assumptions made, the rough data provide a basis for further life cycle analysis.

For adaptive buildings, functional units can be identified and defined from the design that allows for comparability with regard to their properties such as structural elements or estimates for the type of actuators. As an overall analysis of the building does not provide clear comparability due to different functional systems, it is advisable to consider the Functional System Level. A more detailed examination is possible with further detail level during the design process and the corresponding elaboration, as this requires more precise information on components.

In addition to a comparison of the structural design with other functional systems, in the second phase of the methodology, it is also possible to carry out a hot spot analysis in order to analyze the material and energy flow with high negative environmental impacts in the life cycle and to identify potentials for improvement. With a mass and energy estimation, functional systems are to be examined specifically for their proportional environmental effects by the materials and energy consumption. For the operating expenses of the actuation, both the current environmental profile of the electricity generation and the future electricity generation (the year 2050) are considered. The integration of further future scenarios such as the availability of materials is also conceivable. In this way, the future viability of the adaptive elements is to be considered, which, due to the uncertainty of the use phase, depends in particular on the provision of electricity.

The output for the planning team accordingly offers, on the one hand, an evaluation of current adaptive structural designs with regard to environmental compatibility as well as the possibility of a comparison with variants of the functional system. In the context of the planning of the experimental high-rise building, the result would have supported the comparison of different structural designs with regard to a basis for comparison of the applicability of different materials and their life cycle-related environmental impacts such as the change in the structural elements from steel to wood. Based on the result of the output, the planning participants can identify the most resource-efficient structural design concept in order to contrast these criteria, for example, with the effort for the integration and elaborate it further. If necessary, this evaluation step can be repeated as often as required in the design phase or continuously updated with regard to current planning results.

\subsection{Phase 3: LCA on Component System Level}

Details of the supporting structure in the form of required components are available at the completion of the Execution Planning (Service Phase 5), i.e., by the subsequent preparation of the performance specifications (Service Phase 6: Preparation of Contract Award; and Service Phase 7: Assisting with the Awarding Process).

Phase 3 of the methodology represents a detailing of phase 2 at the Component System Level. This means, for example, that for a detail dimensioning of the structural elements or actuators, different compatible components can be compared with each other in terms of their environmental impact and as the basis for selecting a decision. Therefore, the basis is the availability of detailed component data with the same functional performance. Various actuation concepts with different requirements on the mass demand such as parallel or serial actuation [10] can also be used in this context. The evaluation on the basis of performance specifications provides the last possible stage of assessment in order to integrate changes into current planning and can be understood as the last target control before the building will be realized. Ideally, environmental impacts have already been assessed during the Execution Planning, so that the results can be integrated into decisions with less modification effort.

After tendering based on the prepared performance specifications to the corresponding construction firms, changes should generally be avoided, as these result in high costs and time expenditure. The performance specifications already contain detailed mass data and thus represent a precise data source for the assessment of the required resources. However, the final energy demand for the actuation and operation of the building can still only be estimated on the basis of external 
influences, the use-scenarios or calculations based on it. Phase 3 must therefore also consider future developments such as future electricity generation.

During the planning of the experimental high-rise building, two concepts of an adaptive column were discussed, which represented different variants of steel construction. Supported by the analysis in phase 3, the decision-making could have been carried out on the basis of the environmental aspects and not only on the basis of financial and time aspects. The LCA analysis of one of the two column concepts is presented in more detail in Section 7.

\subsection{Phase 4: LCA on Overall System Level}

The fourth phase aims to assess the building after the realization. At this stage, the total amount of material masses actually installed is determined and must be summated. In addition, the actual final energy demand of the sensor-actuator system could be measured during operation. For the first time, both data can be examined as valid values in an LCA for the respective building at this stage. The final energy demand can be determined by an electricity meter and the material requirements, for example, by bills of delivery for building materials and components. Depending on demand, the building as a whole or its components separately can be examined. A complete assessment of the realized building can be prepared on the basis of existing tools for the preparation of life cycle assessments in construction such as Generis [33]. However, the timing of the energy measurement must be considered as influences of external impacts (such as significant wind situation), which have an effect on the LCA results that might not always be present during the entire life cycle. Thus, a longer observation period is required or an analysis of statistics of wind loads occurring and their frequency.

The validation of this phase will be carried out with the completion of the high-rise building in a further research process. By measuring the effective values, the prognoses of the previous evaluation steps can be analyzed and compared with regard to occurring differences. By this means, the experience can be gained for future estimations in the first, second, and third phases of this methodology. In addition, each building assessed in the fourth phase can serve as a reference example or benchmark for the potential determination in the first phase of the subsequent planning of an adaptive building.

After the presentation of all methodology phases, it can be summarized that several LCA-types for the respective usable databases are considered. Figure 5 summarizes the planning stages according to the available level of detail and the respective databases. 


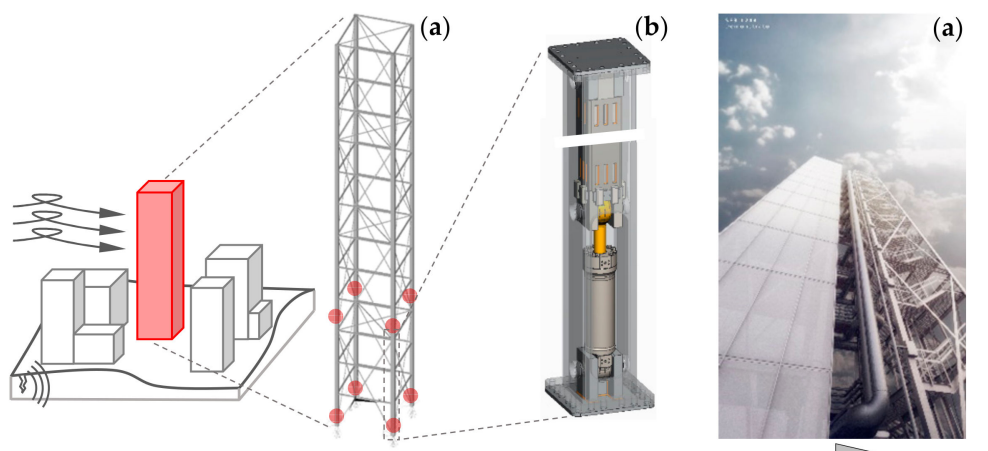

Detailing during planning process

\begin{tabular}{|c|c|c|c|c|}
\hline Planning stage & Basic Evaluation & $\begin{array}{l}\text { Preliminary and } \\
\text { Final Design }\end{array}$ & $\begin{array}{l}\text { Execution } \\
\text { Planning and } \\
\text { Awarding Process }\end{array}$ & $\begin{array}{l}\text { Project Super- } \\
\text { vision / Building } \\
\text { Operation }\end{array}$ \\
\hline LCA-phase & Benchmark LCA & Prognosis LCA & Detailed LCA & Complete LCA \\
\hline $\begin{array}{l}\text { Determination } \\
\text { of material } \\
\text { requirements }\end{array}$ & $\begin{array}{l}\text { Estimation based } \\
\text { on environmental } \\
\text { influences and by }\end{array}$ & $\begin{array}{l}\text { Estimation based } \\
\text { on extrapolation } \\
\text { and adaptation } \\
\text { variations of the } \\
\text { structure }\end{array}$ & $\begin{array}{l}\text { Determination } \\
\text { based on models } \\
\text { and performance } \\
\text { specifications }\end{array}$ & $\begin{array}{l}\text { Mass } \\
\text { determination } \\
\text { based on billings }\end{array}$ \\
\hline $\begin{array}{l}\text { Determination } \\
\text { of end energy } \\
\text { demand }\end{array}$ & $\begin{array}{l}\text { existing buildings } \\
\text { (benchmarks) }\end{array}$ & \multicolumn{2}{|c|}{$\begin{array}{l}\text { Estimation based on } \\
\text { simulation results or empirical values }\end{array}$} & $\begin{array}{l}\text { Exact } \\
\text { determination by } \\
\text { measurement }\end{array}$ \\
\hline
\end{tabular}

Figure 5. Illustration of the methodology phases and respective databases of the methodology. Figures according to: (a) https://www.ilek-uni-stuttgart.de; (b) https://www.iktd.uni-stuttgart.de.

\section{Validation of the Methodology at the Experimental High-Rise Building}

In this section, an exemplary application of the methodology was carried out using the example of the experimental high-rise building initiated by the research project SFB 1244. The aim was to demonstrate that the methodology described in this article meets the requirements and goals of Section 5. First, this section explains the framework conditions relevant for the investigation and afterward the findings from the implementation are presented separately by phase. Finally, an expert view is presented, which was given by building specialists from the architectural and structural design after introducing the approach of the methodology.

The experimental high-rise building is currently not an optimized adaptive building in terms of resource efficiency, as described at the beginning. For purposes of the research project, to simulate different load cases and to generate dynamic loads in order to investigate different oscillation modes, the cross-sections of the supporting structure of the high-rise had to be dimensioned specifically. The number of bearable load cases and the amounts of this special structure exceed the expected parameters of typical wind and earthquake loads on-site.

For the validation, the planning process of the high-rise building is retrospectively considered up to the current planning stage (Execution Planning) and evaluated by applying the methodology. For this purpose, the interim results, as they were available in the intended phases of the methodology during the planning, were considered in isolation. The fourth phase of the methodology could not be validated due to continuous planning as part of the ongoing research project SFB 1244. The evaluation steps are based on a data collection, which was generated by different planning participants of the high-rise. The architect provides the superordinate data for the entire building as the floor plan layout, while the mass quantities and calculations of the supporting structure are based on investigations by a civil engineer. The analysis of the optimal actuator placement in the structure and the frequency of actuation is investigated by system dynamics engineers and the design of the actuator systems by mechanical engineers. Furthermore, only the retrospective planning phases of an adaptive structure 
can be considered in the validation. Adaptive skins have not yet been completely planned on the basis of the procedure model of Honold et al. [29] and therefore cannot be represented by the methodology.

The methodology and hence the validation is based on the European Standard EN 15978 and is therefore applicable independently of the database. The following LCA was performed and evaluated using the software and database GaBi [34]. A calculation based on databases such as Ökobaudat [28], Generis [33] or eLCA [35] could also be implemented. For the results, the primary energy demand from non-renewable resources (PEne) and the global warming potential (GWP) were determined. In order to consider the future viability of the adaptive elements, a scenario for electricity generation in the year 2050 is considered. The future scenario was based on the EU Reference Scenario for future electricity generation [36]. Accordingly, the current electricity generation in Germany causes $0.6 \mathrm{~kg} \mathrm{CO}$-eq. $/ \mathrm{kWh}$ [34] of greenhouse relevant emissions. In 2050, there will be a reduction to around $0.2 \mathrm{~kg} \mathrm{CO}$-eq./ $/ \mathrm{kWh}[36]$. In addition, $7 \mathrm{MJ} / \mathrm{kWh}$ of non-renewable resources are currently being used for the evaluation [34], the share of which is expected to fall below $4 \mathrm{MJ} / \mathrm{kWh}$ by 2050 [36].

In the following subsections, the validation of phases 1 to 3 of the methodology is presented in sequence. First, the input values upon which the valuation was based are explained, followed by the resulting findings.

\subsection{Phase 1: Screening LCA on Building System Level}

During the Basic Evaluation (Service Phase 1), the following framework conditions were elaborated for the planning of the experimental high-rise building and are shown in Figure 6:

\begin{tabular}{|ll|}
\hline 1) FRAMEWORK CONDITIONS IN BENCHMARK LCA ON BUILDING SYSTEM LEVEL: \\
\hline Use: & Research building \\
Building typology: & High-rise building \\
Location and site: & University of Stuttgart, Campus Vaihingen \\
Building orientation: & Building faces south-west/ main wind direction \\
Gross floor space: & $350 \mathrm{~m}^{2}$ \\
Lifetime: & 12 years \\
Storeys: & 12 \\
Height: & $36 \mathrm{~m}$ \\
\hline
\end{tabular}

Figure 6. Input for validation in Phase 1: Framework conditions on the Building System Level.

The database of reference buildings proposed in the first phase of the methodology is not currently available. However, the basic applicability of the assessment proposal was confirmed by the panel of experts within the research project. An analysis based on the checklist would show that due to the expected non-permanent forces mainly resulting from winds, the integration of adaptive elements into the supporting structure could reduce the consumption of resources. In addition, the building typology of high-rise building results due to the building height and a large surface area for wind loads that can cause the building to oscillate. These oscillations lead to stresses in the structural components, which provide a basis of a possible adaptation of the supporting structure [37].

The conclusion of the validation of this phase is that a superordinate qualitative analysis can be investigated based on the existing framework conditions of the planning phase Basic Evaluation.

\subsection{Phase 2: LCA on Functional System Level}

To validate the second phase of the methodology, the prognostic LCA was performed using a practical example for the Functional System Level. Therefore, the entire supporting structure 
in the level of detail of the Preliminary Design without foundation was investigated for analysis. The supporting structure is shown in Figure 7.

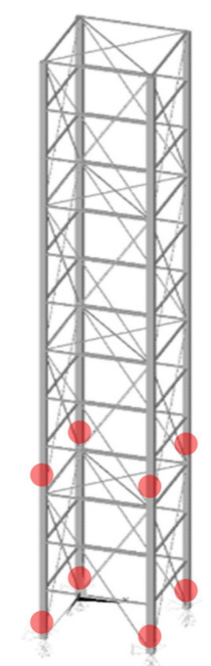

Figure 7. Abstract visualization of the high-rise supporting structure, Figure according to https: //www.ilek-uni-stuttgart.de.

The data used for the prognostic LCA are shown in Figure 8:

\begin{tabular}{|c|c|}
\hline \multicolumn{2}{|c|}{$\begin{array}{l}\text { 2) FRAMEWORK CONDITIONS IN PROGNOSIS LCA ON FUNCTIONAL SYSTEM } \\
\text { LEVEL: }\end{array}$} \\
\hline Structure type: & $\begin{array}{l}\text { Skeleton construction, consisting of columns, } \\
\text { stiffening elements and horizontal beams }\end{array}$ \\
\hline Material: & Construction steel \\
\hline Number and type of actuators: & 24 hydraulic cylinders \\
\hline Circulating hydraulic oil: & Circulating hydraulic oil: 1500 liters \\
\hline Mass of supporting structure: & $47414 \mathrm{~kg}$ \\
\hline Mass of hydraulic cylinders: & $1776 \mathrm{~kg}$ \\
\hline Mass of actuator construction: & $6551 \mathrm{~kg}$ \\
\hline Total mass: & $\underline{55741 \mathrm{~kg}}$ \\
\hline Lifetime: & $\begin{array}{l}100 \text { years (deviating from phase } 1 \text {, since the } \\
\text { experimental high-rise building is to be used for } \\
\text { research purposes for } 12 \text { years, but for } \\
\text { comparability the structure is designed for } 100 \\
\text { years) }\end{array}$ \\
\hline $\begin{array}{l}\text { Final energy demand per year of the } \\
\text { actuation: }\end{array}$ & $\begin{array}{l}4055 \mathrm{kWh} \text { (extrapolation based on measurements } \\
\text { during prototype tests) }\end{array}$ \\
\hline
\end{tabular}

Figure 8. Input for validation in Phase 2: Framework conditions on Functional System Level.

The estimation for the final energy demand was based on the power consumption measurements on a realized prototype [38] of the adaptive steel structure and consisted of $0.2 \mathrm{~kW}$ power energy consumption on standby and $180 \mathrm{~kW}$ by effective actuation. For the estimation of the power energy consumption over 100 years, an actuation time of $12.8 \mathrm{~h}$ per year was assumed. This value resulted from the scenario setup, which provides for the actuation of the structure from a wind speed of $21 \mathrm{~m} / \mathrm{s}$. Wind speeds of more than $21 \mathrm{~m} / \mathrm{s}$ are referred to as storms. The statistics from Germany's National 
Meteorological Service suggest that the site is expected to have an average number of 6.4 storm days per year. In addition, it is assumed that a storm day requires about $2 \mathrm{~h}$ of actuation. It should be noted that this scenario was developed for the validation of the methodology, which has to be proved on the basis of detailed investigations. However, future investigations will enable these assumptions to be validated particularly based on measurement of the realized high-rise building.

The experimental high-rise building is being built for research purposes and is therefore not primarily stimulated by winds. For the experiments, the building can be stimulated to oscillate independently of external influences. The structure is dimensioned in such a way that wind loads do not cause any significant damage even when the actuators are inactive. This characteristic is only useful for the intended test purposes.

The functional equivalent of the structure described above is $350 \mathrm{~m}^{2}$ gross floor area on 12 floors. The system boundary represents the production phase, the actuation in the use phase, and the end of life as the decisive environmental impacts and resource demands are generated in this time. For the operation of the building, the described scenarios of actuation are considered.

Figure 9 shows the LCA results for the supporting structure of the experimental high-rise building. On the left side, the proportional results of the GWPs for Construction (greenhouse gasses consumed by the manufacturing, as well as the end of life processes) and Actuation (greenhouse gasses consumed by the energy demand of the actuation during the operation) are illustrated. The forecast for the year 2050 also shows that the GWP will improve by $50 \%$ just by changing the electricity mix to more renewable energies. On the right side, the results for PEne are shown in the same representation.
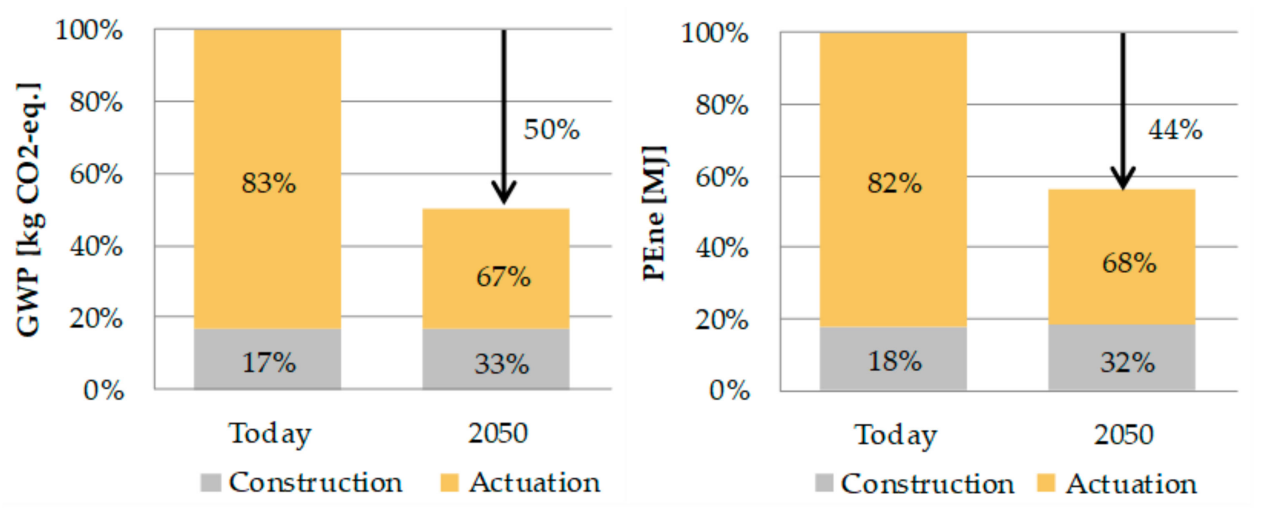

Figure 9. Relative Life Cycle Assessment (LCA) results of the experimental high-rise building in phase 2 for the indicators Global Warming Potential (GWP) and Primary Energy, non-renewable (PEne).

Figures 8 and 9 show that the information basis in the concept stage of the planning of adaptive buildings is sufficient to quantify the environmental impacts. The planning participants can use the result and the output of phase 2 of the methodology as a starting point to critically discuss improvements to the design. Potential for improvements of the adaptive structure system is offered, for example, by reducing the high environmental impact of standby operation. The technical optimization has already been identified for this purpose. In addition, comparisons, e.g., of designs, with different materials, are possible at this point. In summary, it can be stated that phase 2 already provides important findings for the assessment or comparison of different concept variants.

\subsection{Phase 3: LCA on Component System Level}

A detailed representation of the data status of the complete supporting structure would exceed the justifiable effort of the article in order to validate phase 3 of the methodology. Therefore, only an adaptive steel column at the intended level of detail was considered as an example. For this purpose, the production steps necessary for the manufacture of the component of the semi-finished products to be used were considered separately. 
More detailed data, compared to those of the validation of the first phases and that are used as input in this phase, are shown schematically below. Due to the scope of the data, the following list does not include an exact quantity list and an explanation of the processing steps for each component. In addition to the hydraulic cylinder used, the actuator construction also includes the components that are essential for the force transmission above and below the actuator as well as other proportionate functional elements of the hydraulic system. The following information in Figure 10 was collected precisely from the computer-aided design CAD model:

\begin{tabular}{|l|l|}
\hline 3) FRAMEWORK CONDITIONS IN DETAILED LCA ON COMPONENT SYSTEM LEVEL: \\
\hline Structure type: & Supporting column \\
Material: & Construction steel \\
Number and type of actuators: & 1 hydraulic cylinder as part of a parallel actuation \\
& {$[10]$} \\
Mass of supporting structure: & $261 \mathrm{~kg}$ \\
Mass of hydraulic cylinders: & $74 \mathrm{~kg}$ \\
Mass of actuator construction: & $282 \mathrm{~kg}$ \\
Total weight: & $617 \mathrm{~kg}$ \\
Production steps of the supporting & Parameters per column and actuator component \\
structure and actuators: & e.g., welding and powder coating \\
Material type of the columns and & Construction steel \\
actuators: & 100 years \\
Lifetime: & \\
\hline
\end{tabular}

Figure 10. Input for validation in Phase 3: Framework conditions on Component System Level.

Figure 11 illustrates the actuators integrated into the column and the diagonal stiffening element. The presented construction was realized as a prototype of the adaptive structure of the full-size experimental high-rise building [38]. The actuators enable a change in the length of the assigned supporting structure element and thus influence the load transfer. This allows, for example, the damping of oscillations. This article focuses on the actuator integrated into the steel construction of the column (dotted line in Figure 11).

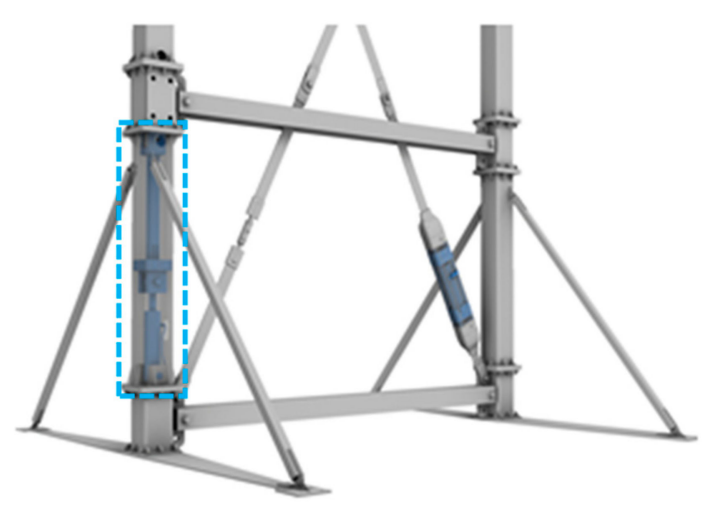

Figure 11. Adaptive steel column of the prototype of the experimental high-rise building of Collaborative Research Centre (SFB) 1244, Figure according to https://www.iktd.uni-stuttgart.de.

The functional equivalent of this analysis was an adaptive column with a total mass of $617 \mathrm{~kg}$ and a length of $2.4 \mathrm{~m}$. The production phase and the end of life represent the system boundary. An actuation in the operation was not analyzed at this point since an assessment without consideration of the 
adjoining components of the support structure equally affected such as the stiffening elements is not representative. However, the scenario explained in the previous subsection could be used again for the comprehensive analysis of the actuation.

Figure 12 shows the results of the GWP for an adaptive supporting column of the experimental high-rise building. Since there was no comparison with another variant, which is elaborated in the same level of detail, the supporting column was evaluated with a hot spot analysis. On the left side, the results are shown proportionally for the production of the supporting structure and actuator technology as well as the end of life. This division in the diagram showed that the production of the actuator had the largest environmental impact. The percentage distribution also roughly corresponded to the mass proportions of the components. On the right side, the GWP for the column production is shown in more detail to identify the largest impact during production. It can be seen that the construction of the actuator, i.e., the production of construction steel, had the largest impact at $82 \%$.

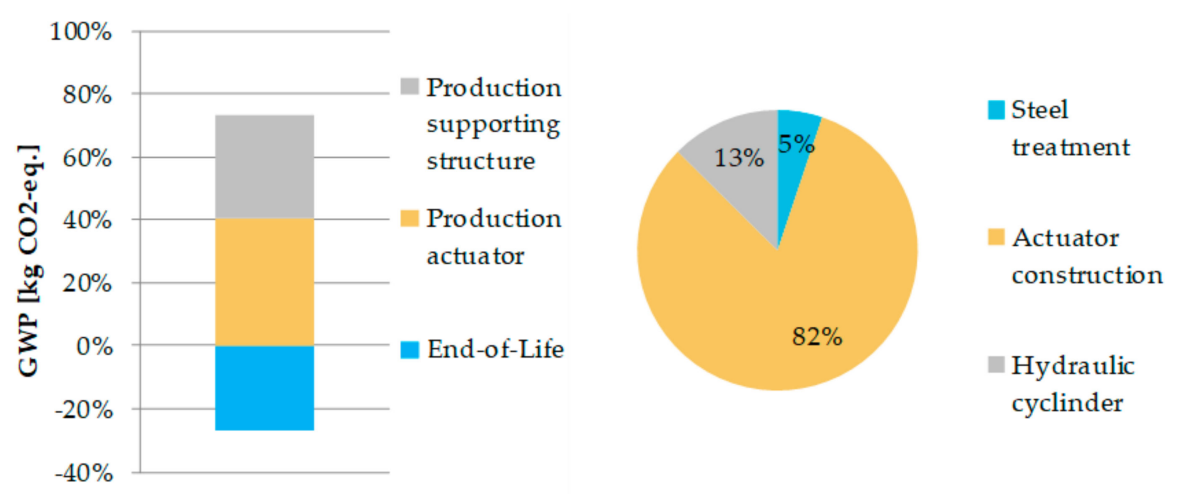

Figure 12. Relative results on adaptive columns in phase 3 for the indicator Global Warming Potential (GWP).

Furthermore, Figure 12 represents an exemplary finding as an output of the third phase of the methodology and the results generate benefits for the planning team. Based on the hotspot analysis, for example, the less complex construction of the actuator should be considered. In addition, the presentation of the GWP indicators shows the ratio of the production of the actuator technology in relation to the column. If necessary, the values can be compared with a passive variant in which no actuators are provided. In this case, the proportion of the column should be correspondingly higher. Due to the detailed examination of the components of the supporting structure, specific optimization approaches can be pursued at this planning stage.

\subsection{Phase 4: LCA on Overall System Level}

Phase 4 will not be considered further at this point, as the experimental high-rise building has not yet reached the phase of Project Control (Service Phase 9) and operation. However, the basic applicability of the evaluation proposal was confirmed by the expert panel within the research project. For validation of the evaluation procedure, it must be seen that the main deviation of the results from the second to the third phase is due to the steel treatment and the refined mass fractions.

In order to examine the results of this contribution in construction practice, the approach of the methodology on the basis of the problem statement and Figures 4 and 5 were introduced to three experts in the field of architecture and structural design. In particular, the applicability from the expert's point-of-view, the necessary information, and framework conditions were verified.

Experts confirmed the need for a systematic consideration of environmental impacts and the applicability at the proposed planning stages. At the present time, experiences on sustainability from previous projects are available, which, however, represent conventional solutions without adaptive systems. This experience must necessarily be extended in the context of adaptive buildings. Due to the effort involved in creating and detailing design variants, these should be preferably analyzed and 
selected during the concept stage. Therefore, the methodology provides an appropriate approach. It was suggested, however, that from the client's point of view the economic aspects should be contrasted and taken up, which have to be examined in a longer-term perspective.

\section{Conclusions and Outlook}

For the development of novel planning phases for adaptive buildings, the expertise of different disciplines is combined. The integration of environmental impacts is of particular importance. The environmental impacts of adaptive buildings are to be identified and reduced in early planning phases. This article answers the research question on which planning stage and detail level an assessment of life cycle-related environmental impacts with the respective available information is possible. The research aim was the early identification of the potential for the reduction of environmental impacts during the design and planning of an adaptive building.

Four planning stages have been identified for the integration of the LCA into the planning process. On one hand, the four planning stages have a sufficient information basis to obtain useful results. On the other hand, they offer the possibility to influence the results in the planning process with regard to resource efficiency and environmental impacts. The phase-based procedure recommends suitable methods for investigations in the respective phases and is therefore called the "Methodology for the reduction of life cycle-related environmental impacts in the planning process of adaptive buildings" (ReAdapt). The main inputs and outputs of the planning phase were identified to carry out a meaningful LCA and to maximize the benefits for planning and design. The validation of the methodology was carried out using the planning results of the experimental high-rise building of the research project SFB 1244. As a result, the first evaluation phase is possible but not yet applicable; the second and third phases could be applied using examples, and the fourth phase is possible, but not yet feasible as the test building has not been completed yet.

With the methodology ReAdapt it will be possible in the future to analyze environmental impacts in the planning process of adaptive buildings. Starting in the early planning phases and continuing through to actual construction, environmental influences such as external loads caused by winds and earthquakes will be integrated in order to carry out estimates and variability comparisons. It is now necessary to further refine the methodology in the field of LCA in order to make it applicable to all adaptive systems of buildings. Especially in the area of adaptive elements, where functions can be shifted within the building, the system boundary and the functional equivalent must be clearly defined. Between the individual phases, it is also conceivable to define target values or to specify framework conditions for the definition of target values. This will enable to assess whether the reduction of environmental impacts was successful.

In addition, it is necessary to calculate further examples of adaptive buildings or adaptive elements in the planning processes and subordinate phases in order to further verify the validity of the method. The validation in Section 7 was elaborated on the basis of the structure. As soon as the skin and the technical building equipment for the high-rise are included in the planning results, the methodology must be re-applied and re-validated. Due to the versatility of skins, new challenges of the method have to be identified. The technical building equipment also offers great potential for minimizing the environmental impact.

The requirements formulated in Section 5 were addressed by the methodology. Only the validation of planning phases 1 and 4 could not be carried out completely for the reasons described. On one hand, phase 4 can only be carried out as soon as the high-rise building enters the operation phase. On the other hand, the adaptive building has to be added to a statistical database on the basis of the described preliminary work.

In the context of the validation described in Section 7 , it has also become apparent that data preparation for the future must be supported. The provision of data for the validation was very time-consuming, so this represents an enormous additional expenditure in the planning phase. One possibility is to link information from the LCA to Building Information Modeling (BIM). 
This implementation would enable the direct identification of the environmental impacts for the design of a building.

Author Contributions: Conceptualization, F.S., C.H., and S.L.; Methodology, F.S., C.H., and S.L.; Validation, F.S. and C.H.; Formal analysis, F.S.; Writing-original draft preparation, F.S., C.H., and S.L.; Writing-review and editing, F.S., C.H., S.L., S.A., D.R., W.H., P.L., H.B., and W.S.; Visualization, F.S., C.H., and S.L.; Supervision, S.A., D.R., W.H., P.L., H.B., and W.S.; Project administration, S.A., W.H., P.L., H.B., and W.S.; Funding acquisition, C.H.; S.A., W.H., D.R., P.L., H.B., and W.S.

Funding: This research was funded by the Collaborative Research Centre 1244 "Adaptive Skins and Structures for the Built Environment of Tomorrow"/project D02 (Life cycle engineering of adaptive skins and structures), and A01 (Development of planning, design and construction methods of adaptive buildings) funded by the German Research Foundation (DFG, Deutsche Forschungsgemeinschaft).

Acknowledgments: The authors are grateful for the generous financial support within the Collaborative Research Centre 1244 and wish to express their gratitude therefor.

Conflicts of Interest: The authors declare no conflict of interest.

\section{References}

1. Deutsche Bundesstiftung Umwelt. Bauen und Wohnen Ressourcen-Schonend Und Energieeffizient; Deutsche Bundesstiftung Umwelt: Osnabrück, Germany, 2013.

2. Haase, W.; Klaus, T.; Schmid, F.; Sobek, W.; Sedlbauer, K.; Schmidt, T.; Synold, M. Adaptive textile und folienbasierte Gebäudehüllen. Bautechnik 2011, 88, 69-75. [CrossRef]

3. Sobek, W. Ultra-lightweight construction. Int. J. Space Struct. 2016, 31, 74-80. [CrossRef]

4. Honold, C.; Binz, H.; Roth, D. Technical planning tasks and participants involved in planning Adaptive Buildings. In Proceedings of the 21st International Conference on Engineering Design, ICED17, Vancouver, BC, Canada, 21-25 August 2017.

5. ISO 14040. ISO 14040-Environmental Management_Life Cycle Assessment-Principles and Framework; ISO: Geneva, Switzerland, 2009.

6. ISO 14044. ISO 14044-Environmental Management-Life Cycle Assessment-Requirements and Guidelines; ISO: Geneva, Switzerland, 2018.

7. DIN EN 15978. Nachhaltigkeit Von Bauwerken-Bewertung der umweltbezogenen Qualität Von Gebäuden—Berechnungsmethode; Beuth Verlag GmbH: Berlin, Germany, 2012. [CrossRef]

8. DGNB. DGNB System, Criteria Set. New Construction Building. 2018. Available online: https://www.dgnbsystem.de/en/system/version2018/ (accessed on 5 August 2019).

9. Schlegl, F.; Gantner, J.; Traunspurger, R.; Albrecht, S.; Leistner, P. LCA of Buildings in Germany: Proposal for a future Benchmark based on existing Databases. Energy Build. 2019, 342-350. [CrossRef]

10. Weidner, S.; Kelleter, C.; Sternberg, P.; Haase, W.; Geiger, F.; Burghardt, T.; Honold, C.; Wagner, J.; Böhm, M.; Bischoff, M.; et al. The implementation of adaptive elements into an experimental high-rise building. Steel Constr. 2018, 11, 109-117. [CrossRef]

11. Schill-Fendl, M. Planungsmethoden in der Architektur: Grundlagen von Planungs- und Entwurfsmethoden Für Architekten komplexer Aufgabenstellungen in Interdisziplinären Gruppen, Dargestellt am Bereich Sozial- und Gesundheitsbauten. Doctoral dissertation, University of Dresden, Dresden, Germany, 2004.

12. HOAI. HOAI 2013-Textausgabe/HOAI 2013-Text Edition; Springer Fachmedien Wiesbaden: Wiesbaden, Germany, 2013. [CrossRef]

13. Lorenz, P. Gebäude Entwerfen: Grundlagen, Methoden, Arbeitshilfen, 1st ed.; Deutsche Verlag Anstalt: München, Germany, 2010.

14. Landowski, D. Einzel-Oder Generalplaner—Die Optimale Planereinsatzform; Springer: Berlin/Heidelberg, Germany, 2017. [CrossRef]

15. Weber, S. Betoninstandsetzung; Springer Fachmedien Wiesbaden: Wiesbaden, Germany, 2013. [CrossRef]

16. Bergmann, C. Prozessneugestaltung im Bauen: Eine Strategie. Doctoral dissertation, University of Stuttgart, Stuttgart, Germany, 2013. 
17. Lange, U.; Oberender, C. Ressourceneffizienz Durch Maßnahmen in der Produktentwicklung, VDI ZRE Kurzanalyse Nr. 20. 2017. Available online: https://www.ressource-deutschland.de/fileadmin/user_ upload/downloads/kurzanalysen/VDI-ZRE_Kurzanalyse_Nr._20_Produktentwicklung_bf.pdf (accessed on 5 August 2019).

18. Ritthoff, M.; Rohn, H.; Liedtke, C.; Merten, T. MIPS berechnen. Ressourcenproduktivitaet von Produkten und Dienstleistungen: Ressourcenproduktivität von Produkten und Dienstleistungen; für Klima Umwelt Energie; Wuppertal-Inst: Wuppertal, Germany, 2002.

19. Verbeeck, G.; Hens, H. Life cycle inventory of buildings: A calculation method. Build. Environ. 2010, 45, 1037-1041. [CrossRef]

20. Cabeza, L.F.; Rincón, L.; Vilariño, V.; Pérez, G.; Castell, A. Life cycle assessment (LCA) and life cycle energy analysis (LCEA) of buildings and the building sector: A review. Renew. Sustain. Energy Rev. 2014, 29, 394-416. [CrossRef]

21. Olinzock, M.A.; Landis, A.E.; Saunders, C.L.; Collinge, W.O.; Jones, A.K.; Schaefer, L.A.; Bilec, M.M. Life cycle assessment use in the North American building community: Summary of findings from a 2011/2012 survey. Int. J. Life Cycle Assess. 2015, 20, 318-331. [CrossRef]

22. Saunders, C.L.; Landis, A.E.; Mecca, L.P.; Jones, A.K.; Schaefer, L.A.; Bilec, M.M. Analyzing the Practice of Life Cycle Assessment. J. Ind. Ecol. 2013, 16, 777-788. [CrossRef]

23. Meex, E.; Hollberg, A.; Knapen, E.; Hildebrand, L.; Verbeeck, G. Requirements for applying LCA-based environmental impact assessment tools in the early stages of building design. Build. Environ. 2018, 133, 228-236. [CrossRef]

24. Meex, E.; Knapen, E.; Verbeeck, G. A framework to evaluate the architect-friendliness of environmental impact assessment tools for buildings. In Proceedings of the ECAADe 2017: 35th International Conference on Education and Research in Computer Aided Architectural Design in Europe, Rome, Italy, 20-22 September 2017.

25. BNB. Bundesministerium des Innern, für Bau und Heimat: Bewertungssystem Nachhaltiges Bauen (BNB). 2018. Available online: https://www.bnb-nachhaltigesbauen.de/ (accessed on 5 August 2019).

26. Gantner, J.; Wittstock, B.; Lenz, K.; Fischer, M.; Sedlbauer, K. EeBGuide Guidance Document: Part B: Buildings. In Operational Guidance for life Cycle Assessment Studies of the Energy-Efficient Buildings Initative; Fraunhofer Institut für Bauphysik: Stuttgart, Germany, 2015.

27. Gantner, J.; Both, P.v.; Rexroth, K.; Ebertshäuser, S.; Horn, R.; Jorgii, O.; Schmid, C.; Fischer, M. Ökobilanz-Integration in den Entwurfsprozess. Bauphysik 2018, 40, 286-297. [CrossRef]

28. Gantner, J.; Lenz, K.; Horn, R.; Both, P.v.; Ebertshäuser, S. Ökobau.dat 3.0-Quo Vadis? Buildings 2018, 8, 129. [CrossRef]

29. Honold, C.; Leistner, S.; Roth, D.; Binz, H.; Sobek, W. Anforderungen in der Entwurfsphase des Integralen Planungsprozesses Adaptiver Gebäude. In Proceedings of the Stuttgarter Symposium für Produktentwicklung (SSP), Stuttgart, Germany, 16 May 2019.

30. Honold, C.; Leistner, S.; Roth, D.; Binz, H.; Sobek, W. Method Toolbox for the Multidisciplinary Planning and Development of Adaptive Buildings. In Proceedings of the International Conference on Enginieering Design (ICED19), Delft, The Netherlands, 5-8 August 2019. [CrossRef]

31. DIN EN 1991-1-4/NA: 2010-12, Nationaler Anhang-National Festgelegte Parameter-Eurocode 1: Einwirkungen Auf Tragwerke-Teil 1-4: Allgemeine Einwirkungen-Windlasten; Beuth Verlag GmbH: Berlin, Germany, 2010. [CrossRef]

32. DIN EN 1998-1/NA: 2011-01, Nationaler Anhang-National Festgelegte Parameter-Eurocode 8: Auslegung von Bauwerken Gegen Erdbeben-Teil 1: Grundlagen, Erdbebeneinwirkungen und Regeln Für Hochbau; Beuth Verlag GmbH: Berlin, Germany, 2011. [CrossRef]

33. Fraunhofer IBP; Abteilung Ganzheitliche Bilanzierung (GaBi). Online-Software Generis. 2019. Available online: https://www.generis.live (accessed on 5 August 2019).

34. thinkstep. GaBi ts: Software-System and Databases for Life Cycle Enginieering; Echterdingen, Germany, 1992-2019.

35. Bundesinstitut für Bau-, Stadt- und Raumforschung. eLCA. 2019. Available online: https://www.bauteileditor. de/ (accessed on 5 August 2019). 
36. Capros, P.; de Vita, A.; Tasios, N.; Siskos, P.; Kannavou, M.; Petropoulos, A.; Evangelopoulou, S.; Zampara, M.; Paroussos, L.; Fragiadakis, K.; et al. EU Reference Scenario 2016: Energy, Transport and GHG Emissions. Trends to 2050; European Commission Directorate-General for Energy, Directorate-General for Climate Action and Directorate-General for Mobility and Transport: Luxembourg, 2016.

37. Sobek, W. Ultraleichtbau: Ultra-Lightweight Construction. In GAM 12: Structural Affairs Potenziale und Perspektiven der Zusammenarbeit in Planung, Entwurf und Konstruktion/Opportunities and Perspectives for Cooperation in Planning, Design and Construction; De Gruyter: Berlin, Germany; Boston, MA, USA, 2016; pp. 156-167. [CrossRef]

38. Weidner, S.; Steffen, S.; Haase, W.; Sobek, W.; Honold, C.; Burghardt, T.; Binz, H.; Böhm, M.; Wagner, J.; Sawodny, O. The Integration of Actuation Concepts and Adaptive Elements into an Experimental High-rise Building. In Proceedings of the Seventh International Conference on Structural Engineering; Mechanics and Computation (SEMC), Kapstadt, South Africa, 2-4 September 2019.

(C) 2019 by the authors. Licensee MDPI, Basel, Switzerland. This article is an open access article distributed under the terms and conditions of the Creative Commons Attribution (CC BY) license (http://creativecommons.org/licenses/by/4.0/). 